\section{O uso da cartografia sonora na avaliação da transformação das paisagens sonoras devido à implementação do Plano Estratégico Urbano das Vargens - Rio de Janeiro, Brasil}

\author{
Andrea Queiroz Rego, Maria Lygia Niemeyer
}

Andrea Queiroz Rego é Professora do Departamento de Urbanismo e Meio Ambiente - FAU/UFRJ - Cultura, paisagem e ambiente construído - PROARQ/UFRJ

Maria Lygia Niemeyer é Doutora em Arquitetura; Programa de Pós-graduação em Arquitetura (PROARQ) da Universidade Federal do Rio de Janeiro (UFRJ)

\section{Resumo}

Este trabalho tem como objetivo discutir o impacto sobre a paisagem sonora dos novos parâmetros urbanísticos aprovados para Vargens, um grupo de três bairros, situado na zona oeste da Cidade do Rio de Janeiro. Por estar localizado em área de expansão urbana e sob a influência de investimentos para as Olimpíadas de 2016, esta área sofre forte pressão do mercado imobiliário. A metodologia de avaliação envolveu a comparação dos mapas de ruído da situação atual e cenários futuros visando identificar o potencial impacto quanto ao mascaramento dos sons presentes na paisagem urbana.

Palavras-chave: paisagem sonora, plano estratégico urbano, mapa de ruído.

\begin{abstract}
This paper aims to discuss the impact over the acoustical environmental of the new urban parameters approved to Vargens, a group of three districts, located in the western area of the city of Rio de Janeiro. By being located in the area of urban expansion and under the influence of investments for the 2016 Olympics, the neighbourhood suffers from severe pressure of the real estate market. The evaluation methodology involved comparing the noise maps of the current situation and future scenarios to identify the potential impact masking the sounds present in the urban landscape.
\end{abstract}

Keywords: soundscape, strategic urban plan, noise map.

\begin{abstract}
Resumen
Este trabajo tiene como objetivo discutir el impacto en el paisaje sonoro de los nuevos parámetros urbanísticos aprobados para las Vargens, un grupo de tres distritos ubicados en la zona oeste de Río de Janeiro. Al estar situado en la zona de expansión urbana y bajo la influencia de las inversiones para los Juegos Olímpicos de 2016, esta zona sufre una fuerte presión en el mercado inmobiliario. La metodología de evaluación implicó una comparación de los mapas de ruido de la situación actual y los escenarios futuros para identificar el impacto potencial sobre el mascaramiento de los sonidos presentes en el paisaje urbano.
\end{abstract}

Palabras-clave: paisaje sonoro, el plan estratégico urbano, mapa de ruido.
REGO, Andrea Queiroz, NIEMEYER, Maria Lygia. O uso da cartografia sonora na avaliação da transformação das paisagens sonoras devido à implementação do Plano Estratégico Urbano da Vargens - Rio de Janeiro, Brasil Thésis, Rio de Janeiro, v. 2, n. 2, p. 246-257, jul./dez. 2016

data de submissão: 25/05/2016 data de aceite: 12/09/2016 


\section{Introdução}

- trabalho é o resultado parcial de duas pesquisas relacionadas ao estudo da qualidade do sistema de espaço livre da Cidade do Rio de Janeiro desenvolvida no Programa de PósGraduação em Arquitetura da Universidade Federal do Rio de Janeiro pelo Grupo SEL/RJ, coordenado pela Professora Dra. Vera Regina Tângari. O primeiro envolve o estudo da influência da vegetação e ventilação na paisagem sonora urbana e é coordenado pela Professora Dra. Andrea Queiroz Rego. O segundo estuda o desenvolvimento dos mapas de ruídos e a sua importância no planejamento urbano e é coordenado pela Professora Dra. Maria Lygia Niemeyer.

No Brasil, os estudos de paisagem sonora estão apenas iniciando e o controle da poluição sonora é regido pela norma NBR10151 - Avaliação do ruído em áreas residenciais para o conforto da comunidade local (Tabela 1), que fornece os limites máximos aceitáveis de ruído ambiental, relacionados ao uso da terra em zona urbana.

TABELA 1

Nível de critério de avaliação NCA para ambientes externos, em dB(A) - ABNT - NBR 10151

\begin{tabular}{|l|c|c|}
\hline Tipos de áreas & Diurno & Noturno \\
\hline Áreas de sítios e fazendas & 40 & 35 \\
\hline Área estritamente residencial urbana ou de hospitais ou de escolas & 50 & 45 \\
\hline Área mista, predominantemente residencial & 55 & 50 \\
\hline Área mista, com vocação commercial e administrativa & 60 & 55 \\
\hline Área mista, com vocação recreacional & 65 & 55 \\
\hline Área predominantemente industrial & 70 & 60 \\
\hline
\end{tabular}

Embora os mapas de ruído não sejam exigidos por legislação específica no Brasil, no contexto das universidades e dos grupos de pesquisa, esta metodologia vem sendo desenvolvida e amplamente aplicada em estudos de caso em várias cidades brasileiras.

Nestas pesquisas fica evidente que o enfrentamento do nível de pressão sonora (medidos ou simulados) com os parâmetros de normas técnicas e legislação não é suficiente para avaliar a complexidade do som ambiental.

A abordagem adotada combina avaliações quantitativas (medições e mapas de ruído) e métodos qualitativos (gravações de paisagens sonoras), sendo o 
objetivo principal demonstrar que a paisagem sonora, a morfologia urbana e o clima estão relacionados e tentar definir o grau e os parâmetros dessa relação. Neste artigo, não será abordada a questão climática, enfatizandose apenas as abordagens para a análise da qualidade sonora do ambiente.

\section{A área de estudo e o PEU das Vargens}

Vargens é um território com densidade populacional muito baixa localizado no extremo oeste da Cidade do Rio de Janeiro, com lojas e serviços de pouca relevância com a predominância de uso residencial, com grandes lotes unifamiliares ou condomínios horizontais, entre haras, chácaras de floras e plantações de subsistência. O tráfego de veículos, na maioria das vias, é de baixo fluxo com a presença de muitas bicicletas em ruas, muitas vezes, não pavimentadas.

O plano estratégico urbano - PEU das Vargens, aprovado em 2009, no Município do Rio de Janeiro, incentiva o crescimento da população e a verticalização na maior parte do território e, sua consolidação tem se mostrado muito rápida, devido aos investimentos para as Olimpíadas de 2016 nesta área. Consequentemente, a frota de veículos e as atividades comerciais irão aumentar consideravelmente, aumentando consequentemente o nível de ruído, causando possível desconforto para a população e mascaramento dos principais marcos sonoros locais.

A primeira análise desenvolvida em Vargem foi uma área residencial perto do Parque da Pedra Branca, unidade de conservação ambiental, com acesso pela Estrada "Sacarrão", rua residencial, com aproximadamente $3.000 \mathrm{~m}$ de comprimento, que termina na floresta, onde o nível de pressão sonora gerado não excede ao limite permitido pela legislação vigente, e onde podemos ouvir os sons produzidos pela natureza, como pássaros, anfíbios e o Rio Sacarrão fluindo.

\section{Metodologia}

O principal objetivo é avaliar como o Plano Estratégico Urbano de Vargens, quando implantado, vai alterar a qualidade do som ambiente.

Metodologicamente, o trabalho é desenvolvido nas seguintes etapas:

- pesquisa de campo e documentação da morfologia urbana e dos sons ambientais presentes na paisagem de modo quantitativo e qualitativo; 
- desenvolvimento do mapa da paisagem sonora atual;

- desenvolvimento do mapa de ruído atual com base em levantamento de dados;

- desenvolvimento do mapa de ruído projetado com base nas diretrizes do plano morfológicas e no aumento tráfego de veículos estimado, devido ao crescimento da população;

- análise do crescimento do nível de pressão sonora (NPS) e, consequentemente, dos sons mascarados ou extintos, notadamente, os marcos sonoros locais.

\section{A pesquisa de campo e o armazenamento dos dados}

A equipe de campo é composta por três pesquisadores e três bolsistas de IC, organizados em três pares. Os equipamentos utilizados em campo são: gravador Audio Voz Digital ZOON H4n, câmera digital com GPS Sony DSC HX100V, sonômetro Instrutherm DEC-490, sonômetro Kimo 200 e anemômetro termo-higrômetro luxímetro Instrutherm THAL-300.

A documentação utilizada para esta pesquisa compreende quatro fichamentos distintos: paisagem urbana, paisagem climática, paisagem sonora e paisagem flora e fauna.

A ficha da paisagem urbana inclui os dados de cadastro do ponto - endereço e imagem aérea para a localização -, os dados do levantamento - hora, dia e nome dos pesquisadores - e os dados da paisagem em si - caraterização do espaço edificado contíguo ao espaço livre estudado, uso e apropriação do espaço livre estudado, mobiliário urbano existente, tipo de pavimentação e odores. Os dados coletados por observação em campo são digitalizados e acrescidos de fotos ilustrativas e de uma imagem desenvolvida o Google Earth mostrando a localização.

A ficha da paisagem climática é composta apenas pelos dados climáticos coletados e digitalizados que incluem: temperatura (oC), umidade (\%), condição do céu (escala variando de 1 à 5 onde 1 é céu total sem nuvens e 5 é céu totalmente nublado), sombreamento, radiação ( $\mathrm{W} / \mathrm{m} 2)$, iluminamento (lux), sentido do vento, velocidade do vento $(\mathrm{m} / \mathrm{s})$ e efeito do vento (escala Beaufort). 
A ficha da paisagem sonora (Figura 1), além dos dados de identificação do ponto - data e horário de gravação -, é composta dos dados digitalizados do fichamento de campo - nome do arquivo de gravação, tempo de gravação, descrição do fundo, evento, sinal e marco sonoro, conforme a estrutura criada por Schafer - e dados posteriormente trabalhados - nome do arquivo gravado e editado e seu respectivo tempo, LAeq calculado e gráfico do nível de pressão sonora a partir dos dados registrados no datalogger do sonômetro.

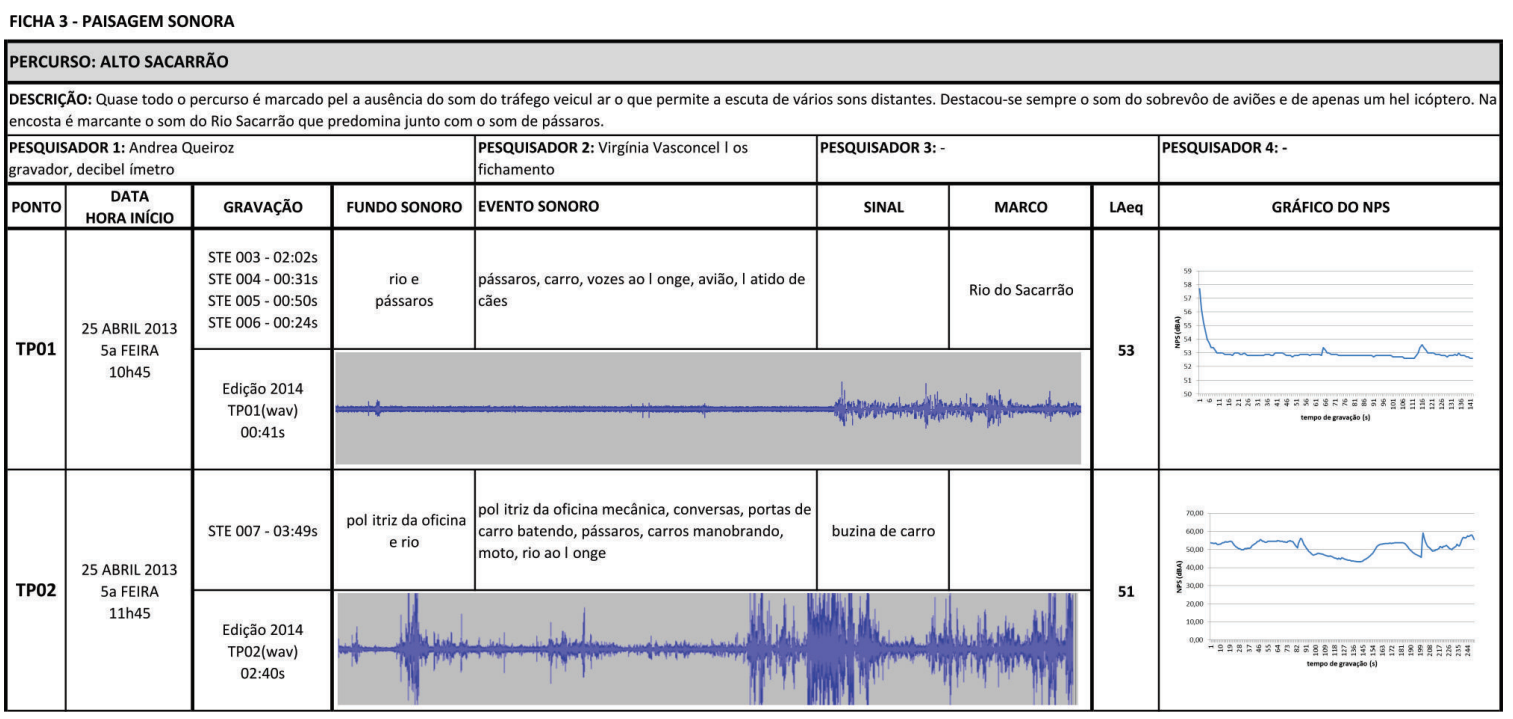

Figura 1

Ficha da paisagem sonora mostrando três pontos de estudo na Estrada do Sacarrão

A ficha para a documentação da Paisagem da Flora e da Fauna, além dos dados de identificação do ponto e do levantamento em si, é composta dos dados de campo digitalizados e da inclusão de imagens geradas no Google Earth que permite a caracterização da cobertura do solo e de fotos que representem os grupamentos vegetais, elementos vegetais de destaque e a fauna observada.

\section{O mapa sonoro atual}

O mapa de paisagem sonora (Figura 02) é uma representação qualitativa com base na ficha de campo - Paisagem Sonora, que usa os conceitos de Schafer - fundo sonoro, evento sonoro, sinal sonoro e marco sonoro, para a sua estruturação, tendo como principal objetivo proporcionar uma "leitura" da paisagem sonora para qualquer pesquisador que esteja envolvido no planejamento de espaços mas não seja um especialista em acústica.

Deste modo, sobre uma imagem do Google Earth, tomada à $200 \mathrm{~m}$ de altura aproximadamente, para ser possível observar o tipo de cobertura do solo (terra 
exposta, forração vegetal, campo agrado, fragmento florestal etc), a malha viária, o tipo de edificação e a densidade ocupacional, é marcado o percurso estudado e nele os pontos de medição e gravação sonora. Em cada ponto, são atribuídas três tipos de informações: a foto do lugar, os sons através de símbolos e os ventos.

Os sons de fundo, isto é, aqueles presentes durante todo o tempo da gravação são representados por ícones pretos. Os eventos sonoros, isto é, conjuntos de sons indissociáveis que têm aparição por um certo intervalo de tempo na gravação, são representados por símbolos azuis. Os sinais sonoros, sons de alerta que nos chamam a atenção para algum fato em função de um código cultural ao qual estão associados, são representados por símbolos vermelhos. Os marcos sonoros, isto é sons memoráveis que devem ser preservados pois são capazes de identificar o lugar de modo diferenciado para aqueles que o vivenciam, são representados com símbolos sobre quadros brancos, isto é podemos ter um fundo sonoro, um evento sonoro ou mesmo um sinal sonoro memorável.

Os ventos, que contribuem para a alteração da propagação sonora, têm sua direção, sentido e velocidade representados por setas, sendo a largura das setas proporcional a velocidade dos ventos.

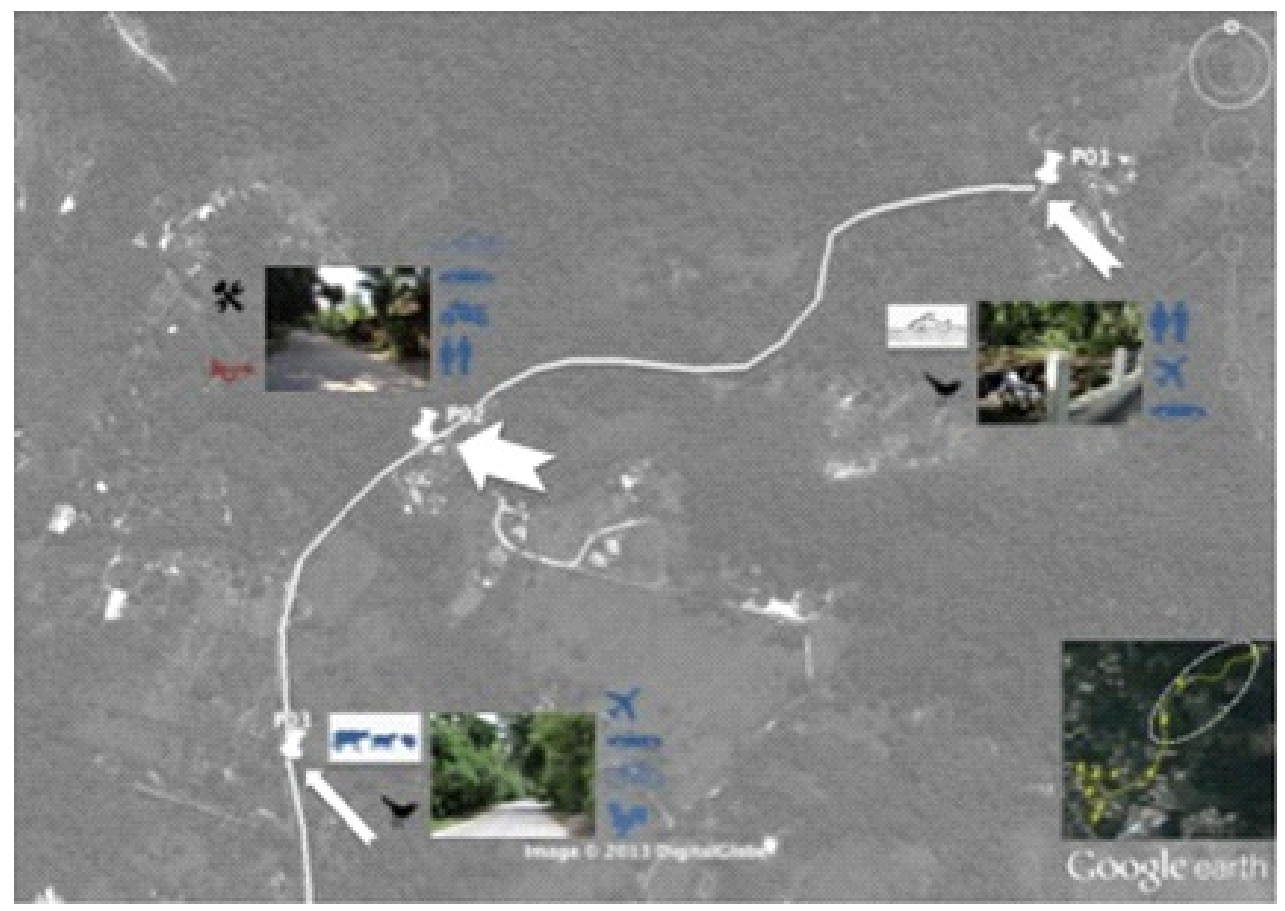

Figura 2

Mapa da paisagem sonora, onde os sons de fundo são representados em preto, os sons dos eventos sonoros em azul, os sons dos sinais sonoros em vermelho e dos marcos sonoros em branco.

Fonte: Desenvolvido pelas autoras 


\section{O mapa de ruído atual}

Os mapas de ruído foram criados usando os procedimentos já avaliados em outras pesquisas, utilizando o software Soundplan, versão 7.2. A fim de gerar o modelo digital as informações básicas sobre a topografia (curvas de nível e pontos cotados), sobre a rede viária (comprimento e largura das vias), e sobre as edificações (forma e ocupação do lote) foram importados do levantamento cadastral digital do Município do Rio de Janeiro. As informações relacionadas com os edifícios (uso do solo e gabarito) e sobre as áreas livres (massa vegetal e pavimentação) foram importadas do banco de dados desenvolvido pelo Grupo SEL/RJ que utilizou ortofotos, levantamento de campo e sobrevoo de helicóptero.

Como não há outra fonte de ruído significativa na área de estudo, para a quantificação das emissões foi considerada apenas o tráfego rodoviário. Exceto na Estrada dos Bandeirantes (78,371 veículos/dia, dados do Departamento de Trânsito do Rio do Janeiro), não há dados de fluxo de tráfego disponíveis para as ruas da área de estudo. O mapa de ruído atual foi baseado em medidas de campo. O nível de pressão sonora contínuo equivalente ponderado em " $A$ " (LAeq) foi medido por 10 minutos em cada ponto de recebimento da Estrada do Sacarrão e suas ruas secundárias (Tabela 02). O equipamento utilizado foi um medidor de nível de pressão sonora integrada Kimo 200, previamente calibrado. Simultaneamente às medições foi feita a contagem de veículos (leves, pesados e motos) e as informações registradas necessárias para caracterizar a composição do tráfego (número e direção de vias, pavimentação de estradas, calçadas e ruas secundárias).

A calibração do modelo com as medições de campo e registro de dados é fundamental para corrigir possíveis distorções geradas pelas características locais, uma vez que o Soundplan, bem como outros programas de mapeamento acústico comercializados no Brasil, foi desenvolvido a partir de parâmetros estabelecidos pela Directiva 2002/49/CE. A maioria das ruas secundárias apresentam um pequeno e intermitente de fluxo de veículos.

O mapa de ruído da situação atual (Figura 03) apresenta níveis de ruído um pouco maior na porção inicial da Estrada do Sacarrão, área com mais residências e tráfego. De qualquer forma, em toda a maior parte da estrada e das ruas secundárias, o nível de ruído é mantido em torno de $65 \mathrm{~dB}(\mathrm{~A})$, sendo atenuado pelas grandes massas vegetais e pelo solo exposto ou com forrações vegetais que colaboram na absorção sonora. 
TABELA 2

CONTAGEM DE TRÁFEgo NA ÁREA do SACARRÃo E LAEQ

\begin{tabular}{|l|c|c|}
\hline Ponto de recep ção & $\begin{array}{c}\text { Veículos /10 } \\
\text { min }\end{array}$ & LAeq \\
\hline Est. dos Bandeirantes & 815 & 70,7 \\
\hline Est. do Sacarrão (0) & 69 & 74,1 \\
\hline Est. do Sacarrão (1) & 70 & 63,3 \\
\hline Est. do Sacarrão (2) & 36 & 65,1 \\
\hline Est. do Sacarrão (3) & 7 & 56,5 \\
\hline Est. do Sacarrão (4) & 10 & 56,5 \\
\hline R. Agapanto & 10 & 55,5 \\
\hline R. Luciano Gallet & 5 & 54,7 \\
\hline R. Serra Dourada & 5 & 70,5 \\
\hline R. C. Nascimento & 1 & 56,5 \\
\hline R. Lagoa Bonita & 12 & 60,7 \\
\hline
\end{tabular}
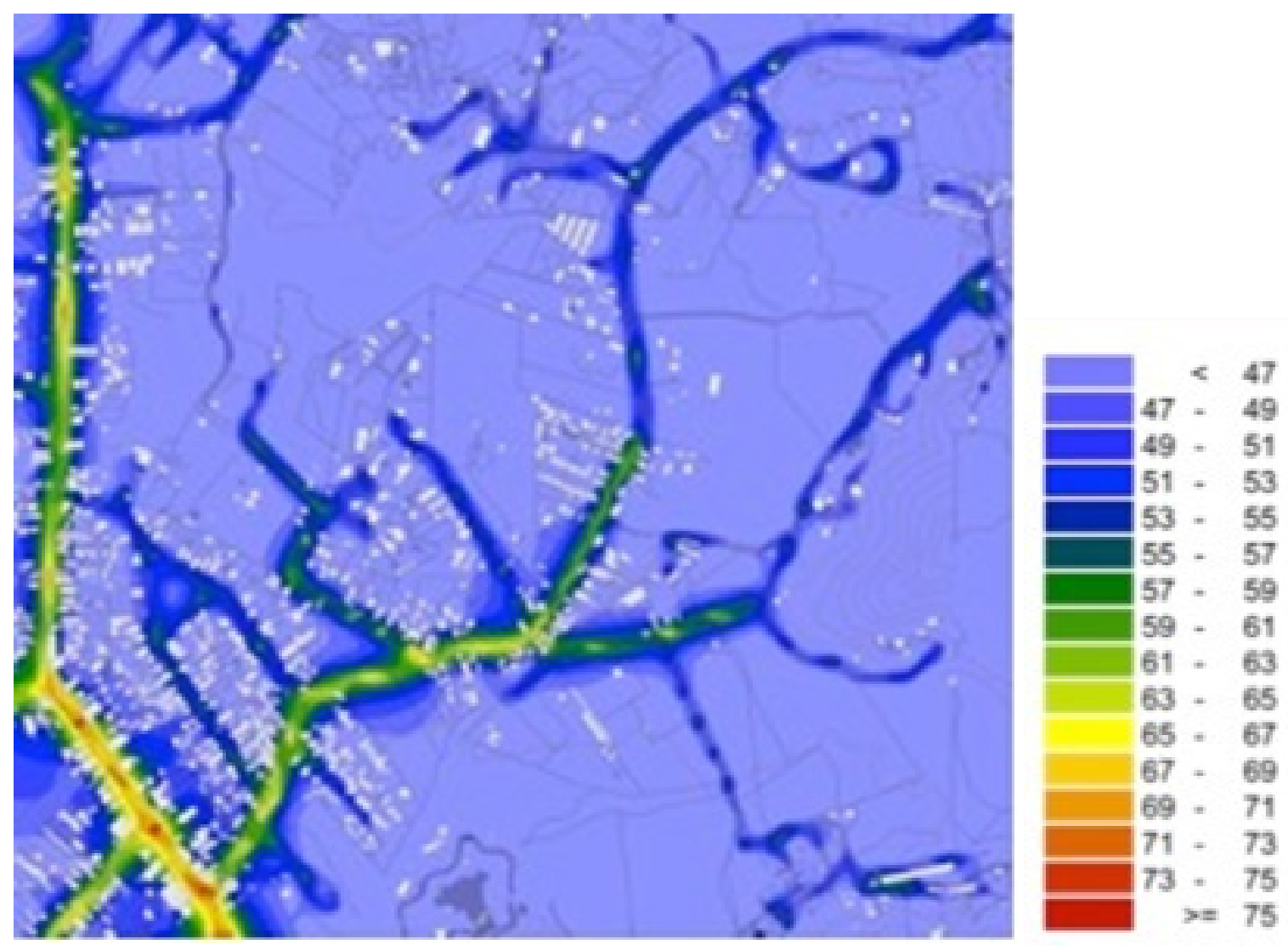

Figura 3

Mapa de ruído atual.

Fonte: Desenvolvido pelas autoras 


\section{O mapa de ruído projetado}

O conjunto formado pela construção e legislação urbanística certamente exerce grande influência sobre a configuração espacial do espaço construído. Por um lado, o uso do solo e forma de ocupação (parâmetros de dimensionamento de lotes, taxas de ocupação, indicadores e coeficientes de utilização) limitam a forma, o volume e a variedade total de área construída. Por outro lado, estes parâmetros podem ser expressos a partir de várias soluções. Portanto, a modelagem de cenários futuros para a avaliação do impacto de previsão deve emanar de premissas e critérios para a interpretação da legislação, de preferência dentro de um horizonte de tempo definido.

O cenário futuro usado para simular o impacto do ruído foi estudado e definido pelo grupo SEL/RJ, com base nas normas e tipologias comumente implantadas pelo mercado imobiliário após a aprovação do PEU das Vargens. O padrão tipológico que foi replicado na área são condomínios que mesclam o uso multifamiliar com o uso unifamiliar, com 2 e 3 quartos por unidade, gerando grande ocupação relvados vazios, com acesso através das vias existentes.

As estimativas do aumento de tráfego foram baseadas nos parâmetros de geração de viagem estabelecidas para o uso residencial na Cidade do Rio de Janeiro. Se comparado com os outros usos do solo permitidos na área (comércio e serviços), o uso residencial é o que gera menor fluxo de tráfego. No entanto, devemos considerar o número significativo de unidades residenciais a serem implantados e a distância entre os edifícios e os transportes públicos.

Deste modo, o mapa de ruído projetado foi criado no Soundplan usando a base morfológica desenvolvida pelo Grupo SEL/RJ e as estimativas do aumento do volume de tráfego. O resultado indica um aumento significativo do nível de pressão sonora ao longo de toda a estrada e a penetração do som nas ruas circundantes que se tornam áreas contaminadas pela propagação do som do tráfego veicular.

\section{Análise comparativa}

A análise comparativa (Figura 4) usa o mapa de ruído projetado como uma base para introduzir os aspectos atuais da paisagem sonora, isto é dados do mapa sonoro. Com isto, é possível comparar que sons atuais são compatíveis com o cenário prospectivo, avaliando 
o nível de pressão sonora e tipo de fonte ou de uma prática social que produz um som específico que tem a potencialidade de serem mascarados, deixando de ser escutados, ou mesmos extintos.

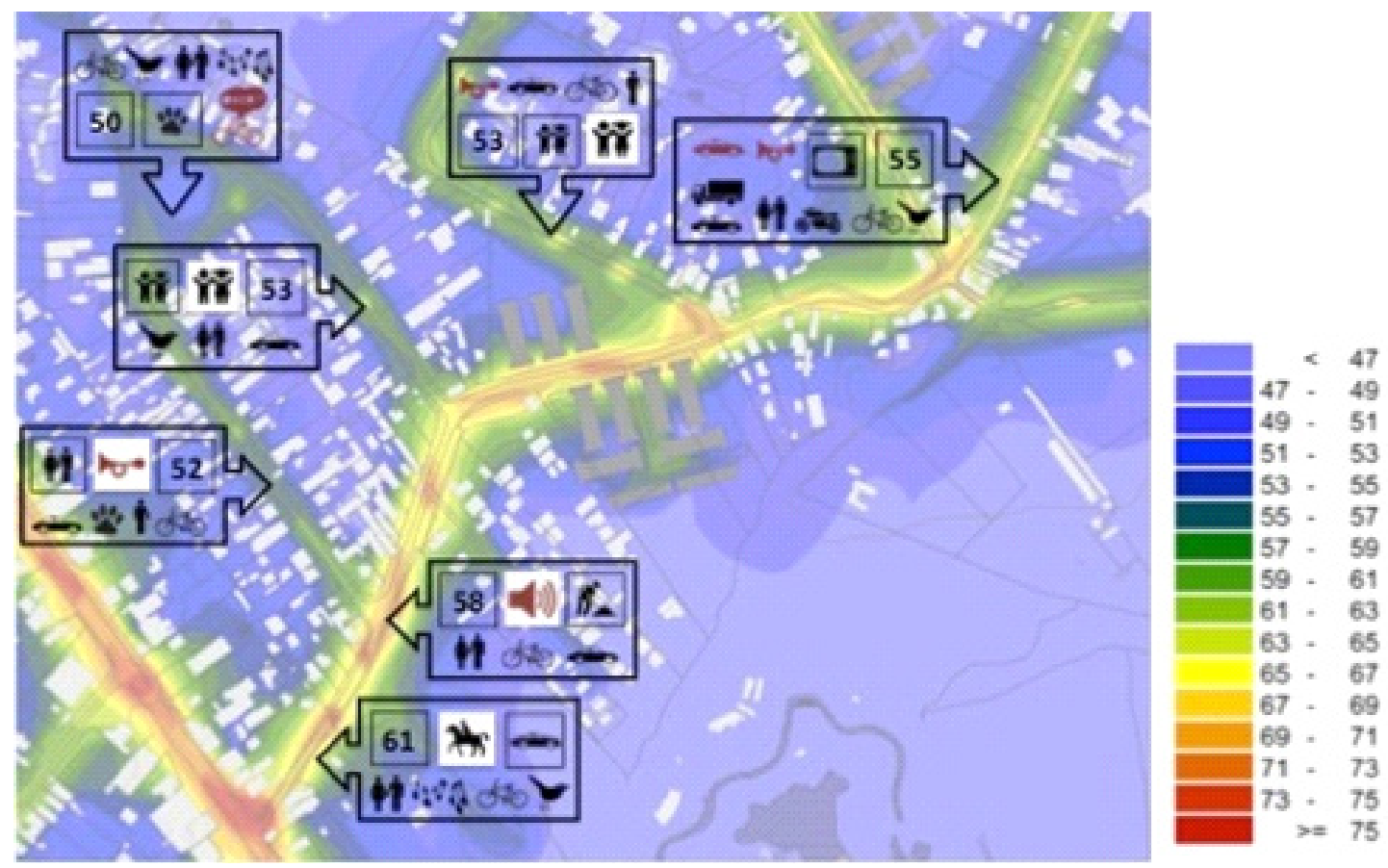

Figura 4

Mapa de ruído atual.

Fonte: Desenvolvido pelas autoras

\section{Resultados alcançados}

$\mathrm{Na}$ área da Estrada do Sacarrão pode ser verificado que os níveis de pressão sonora futuros produzidos pelo aumento do tráfego de veículos vai mascarar a maioria dos "pequenos" sons presentes na paisagem sonora de hoje em dia. O nível de pressão sonora atual, ao longo da Estrada do Sacarrão, que oscila entre $55 \mathrm{~dB}(\mathrm{~A})$ e $61 \mathrm{~dB}(\mathrm{~A})$, será mascarada pelos níveis de pressão sonora projetados, observando-se os valores entre $65 \mathrm{~dB}(\mathrm{~A})$ e $73 \mathrm{~dB}(\mathrm{~A})$.

Talvez, nas estradas secundárias a paisagem sonora atual poderia continuar a ser escutada e o modo de vida urbana poderia ser preservado com crianças brincando nas ruas, pessoas sentadas e conversando nas calçadas, padeiros vendendo pão nas suas bicicletas, pessoas andando à cavalo ou assistindo TV sentadas na calçada, mas ao longo da Estrada do Sacarrão dificilmente esses comportamentos serão mantidos com a nova morfologia proposta.

Provavelmente, todos os sons da natureza - uma grande variedade de pássaros, o rio que flui, o som dos insetos e sapos - terão sua escuta reduzida ou mascarada. 


\section{Considerações finais}

A pesquisa incluiu outras áreas de estudo ao longo do transecto geográfico da Subbacia dos Canais que abrange parte dos bairros de Vargem Grande e Recreio dos Bandeirantes, a partir do Parque da Pedra Branca até o oceano.

Avaliou-se neste transcecto 4 (quatro) unidades de paisagem: a primeira (UP1) corresponde à área de proteção permanente, encosta florestada responsável pelos mananciais da região; a segunda (UP2) corresponde ao trecho de transição da baixada e encosta, com ocupação de baixa densidade, com algumas glebas ainda com produção rural, sendo a maior parte ocupada por lotes unifamiliares; a terceira (UP3) corresponde à área da baixada constituída por grandes glebas em "regime de engorda imobiliária", isto é com enorme potencial de ser ocupada por grandes loteamentos; e a quarta (UP4) equivale à área do Bairro do Recreio dos Bandeirantes com ocupação urbana consolidada de média densidade ocupacional onde predominam edificações multifamiliares de até 3 pavimentos. Excetuando a Unidade de Paisagem 4, nas demais unidades se verifica uma potencial e significativa mudança na paisagem sonora.

O grande avanço conceitual foi consolidar a diferença entre paisagem sonora e ruído urbano, destacadamente, causado pelo tráfego veicular. Esta diferenciação conceitual fica mais evidentemente estabelecida através da criação desta nova cartografia sonora - mapa e espectograma sonoro, bastante diferenciado de um mapa de ruído, isto é, houve, reconhecidamente, um grande avanço no campo da representação gráfica de paisagem sonora, uma vez que esta cartografia foi apresentada em eventos de diferentes naturezas científicas, tanto nacionais quanto internacionais - de estudos da morfologia urbana, de conforto ambiental, de estudos da paisagem, de acústica urbana e de paisagem sonora - sendo sempre objeto de questionamento, debate e evolução dentro do grupo de pesquisa.

O estudo dos sons como forma de expressão cultural auxilia na compreensão da complexa rede de relações de uma cidade. Os sons podem ser associados às transformações urbanas e às diversas formas de apropriação do espaço, visto que são representações culturais de diversos atores e, fornecem indícios sociais e econômicos, do modo de viver. 
Os sons e os demais elementos imateriais, como a luz e o calor, juntamse aos elementos materiais, formas e texturas, para qualificar os ambientes. Vários estudos mostram como os diferentes tipos de sons alteram, direta ou indiretamente, as reações humanas e colaboram para as sensações de paz, aconchego, isolamento, insegurança, solidão, medo... Isto só é possível porque, entre o "silêncio" e o "ruído", existe uma infinita variedade de sons e de escutas. Analisar um ambiente urbano levanto em consideração tanto a sua paisagem sonora quanto a poluição sonora é uma questão de estética e qualidade do ambiente. É imprescindível perguntar que tipo de características acústicas os espaços nos quais vivemos devem ter e não apenas se são ou não ruidosos.

O planejamento urbano das cidades brasileiras não pode ignorar o planejamento sonoro, este deve ser incorporado de modo que os sons, na sua totalidade, também, sejam incluídos como elementos de estruturação urbana como o uso de mapas de ruídos evitando que ricas estruturas sonoras com valor cultural não sejam suplantadas pelo ruído do tráfego veicular, de forma uníssona.

\section{Referências}

ABNT- Associação Brasileira de Normas Técnicas. NBR-10151. Acústica: Avaliação do Ruído em Áreas Habitadas Visando o Conforto da Comunidade: Procedimento. Rio de Janeiro, 2000.

BARRETTO, D. M. e FREITAS, I. M. D. P. Importância de mapas de ruído na análise do planejamento dos transportes, Anais do XXII Encontro da Sociedade Brasileira de Acústica, Belo Horizonte, 2008.

CORTES, Marina M. e NIEMEYER, Maria Lygia. Avaliação do Impacto Sonoro Resultante da Verticalização no Bairro Residencial de Petrópolis, Natal-RN. In: Actas do $5^{\circ}$ Congresso Luso-Brasileiro para o Planejamento Urbano, Regional, Integrado e Sustentável. Brasilia/ DF, 2012.

Prefeitura da Cidade do Rio de Janeiro. Decreto Lei N. 104 de 27 de Novembro de 2009.

REGO, Andrea Queiroz e NIEMEYER, Maria Lygia. Qualidade Sonora e Clima Urbano: cotejando dimensões invisíveis. Anais do II Encontro ENANPARQ. Natal, 2012.

SCHAFER, R. Murray. The soundscape - our sonic environmental and tuning of the world. Rochester: Destiny Books, 1994. 